\title{
WIND TUNNEL TESTS OF HOW COASTAL PLANTS FEEDBACK ON DUNE SHAPE
}

\author{
Bianca Charbonneau, University of Pennsylvania, bcharbon!@sas.upenn.edu \\ Brenda Casper, University of Pennsylvania, bcasper@sas.upenn.edu
}

Theoretical evolution of a coastal dune system starts at the individual plant level with the formation of bedforms, nebkha and shadow dunes, around plants. Over time, these initial bedforms can evolve into a fully developed foredune and eventually a complex dune system capable of buffering upland coastal areas against high tides and storms. Recent studies suggest that dunebuilding plant species may differ in their sand trapping efficiency and they may support different topographies, building dunes morphologically similar to their own stature - i.e. a taller steeper plant would build a taller and steeper dune. We believe that the bedforms created at the onset of dune evolution, i.e. after a storm or at the backbeach, may carry over through the life of the dune, such that understanding how plant morphology and density affects the initial formation stages of dune morphology is key to optimizing dune management, maintenance, and creation. With ERDC and USGS funding, we built a removable bed unilateral flow wind tunnel (Figure 1) to test how the morphology among and within dominant US East coast foredune plants feeds back on bedform creation around individual plants at a baseline of zero (i.e. flat back beach or post storm). The wind tunnel is capable of reaching a max speed of 12.1 $\mathrm{m} / \mathrm{s}$ and was designed for adaptability beyond the scope of this research. It has a $6 \mathrm{~m}$ chamber with a $1 \mathrm{~m} \times 2 \mathrm{~m}$ cross sectional area. Pre-fabricated boxes, $1 \mathrm{~m} \times 1 \mathrm{~m} \times$ $0.3 \mathrm{~m}$ can be inserted and sealed into the wind tunnel $3.6 \mathrm{~m}$ downwind such that a continuous sand bed can be created within the chamber upwind of the test area to replicate the conditions of the initial stage of dune evolution. We tested different planting densities, commonly used in planting efforts, specifically $15 \mathrm{~cm}, 30$ $\mathrm{cm}$, and $45 \mathrm{~cm}$ on center. Our plants include native American Beachgrass (Ammophila breviligulata), invasive Asiatic Sand Sedge (Carex kobomugi), and native Bitter Panicgrass (Panicum amarum) as the dominant mid-Atlantic dune building and stabilizing species. We had four box replicates per density per species as well as four null boxes with only sand and no plants $(\mathrm{N}=40)$. We measured various morphological parameters of the plants in each box, such as height, width, and number of leaves and stems, and then subjected each box to 30 minute experimental runs at $8.25 \mathrm{~m} / \mathrm{s}$. Post-experiment, we used a 3D sensor built into the wind tunnel to scan the resulting topography, i.e. the bedform accumulation around the individual plants, with sub-millimeter accuracy. By knowing the morphology of each plant in a box, we were able to attribute bedform morphology, size and shape, to plant morphology, as well as to biomass after harvesting all plants post-trial (Figure 2). We found that plant species varied in morphology and biomass was the most informative morphological variable. Bedforms formed in all experimental trials and we are able to see differences in accumulation as a function of species and biomass as effects. Bedforms did not form in the absence of plants in null trials that contained only sand with no plants. This research is ongoing. Coastal dunes are unique systems and information needed to inform management spans a variety of disciplines. Therefore, this work and all future work will approach the topic with a multifaceted perspective spanning ecology, sedimentology, geology, and conservation management. Information about how plants shape dunes will become more important with time as storms continue to grow more frequent, severe, and unpredictable with climate change.

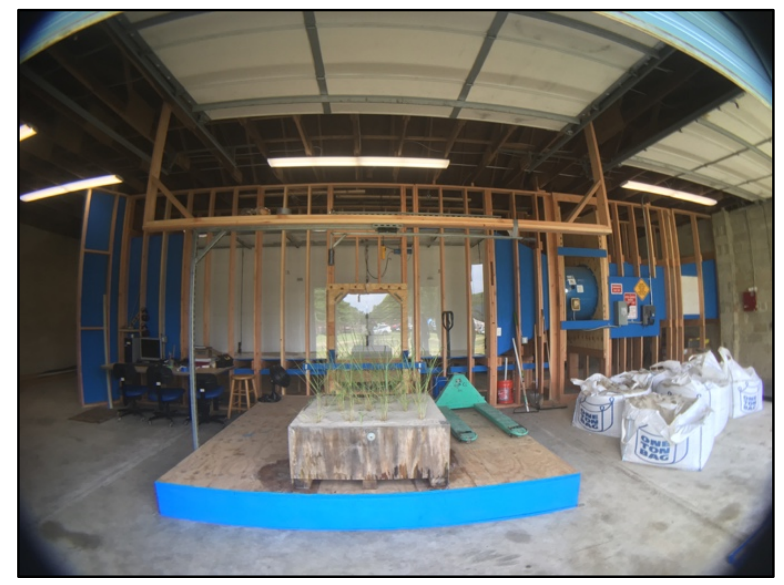

Figure 1 - Removable bed unilateral flow wind tunnel.

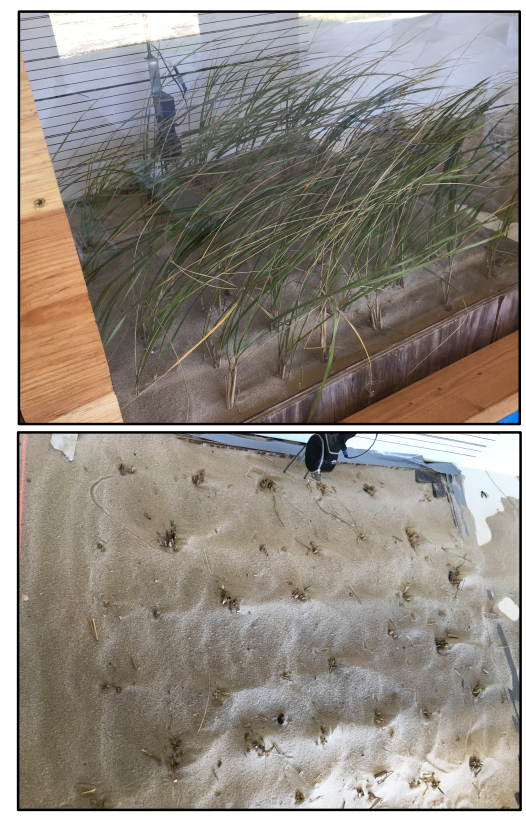

Figure 2 - A high density, $15 \mathrm{~cm}$ spacing, Ammophila box during an experiment $\&$ the same box post-experiment after aboveground biomass was removed to 3D scan the resulting underlying topography. 